\title{
Co-seismic surface effects from very high resolution panchromatic images: the case of the 2005 Kashmir (Pakistan) earthquake
}

\author{
M. Chini, F. R. Cinti, and S. Stramondo \\ Istituto Nazionale di Geofisica e Vulcanologia, Rome, Italy \\ Received: 17 June 2010 - Revised: 1 September 2010 - Accepted: 20 September 2010 - Published: 25 March 2011
}

\begin{abstract}
The use of Very High Resolution (VHR) satellite panchromatic image is nowadays an effective tool to detect and investigate surface effects of natural disasters. We specifically examined the capabilities of VHR images to analyse earthquake features and detect changes based on the combination of visual inspection and automatic classification tools. In particular, we have used Quickbird $(0.6 \mathrm{~m}$ spatial resolution) images for detecting the three main coseismic surface features: damages, ruptures and landslides. The present approach has been applied to the 8 October 2005, $M_{\mathrm{w}} 7.6 \mathrm{Kashmir}$, Pakistan, earthquake. We have focused our study in and around the main urban areas hit by the above earthquake specifically at Muzaffarabad and Balakot towns. The automatic classification techniques provided the best results wherever dealing with the damage to man-made structures and landslides. On the other hand, the visual inspection method demonstrated in addressing the identification of rupture traces and associated features. The synoptic view (concerning landslide, more than 190 millions of pixels have been automatically classified), the spatiotemporal sampling and the fast automatic damage detection using satellite images provided a reliable contribution to the prompt response during natural disaster and for the evaluation of seismic hazard as well.
\end{abstract}

\section{Introduction}

In destructive events, a prompt overview of the damage to human settlements and landscape changes is a relevant issue to manage the rescue efforts and, subsequently, to organize restoration activities (Chini et al., 2008a; Stramondo et al., 2008). Very High Resolution (VHR) satellite panchromatic

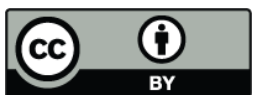

Correspondence to: S. Stramondo (salvatore.stramondo@ingv.it) images have revealed to be a reliable tool to detect surface effects of natural disasters. Data from these sensors (i.e. QuickBird, Ikonos, WorldView-1 and 2, GeoEye-1) have a potential for more exhaustive mapping of the environment with details at sub-metre resolution.

The 8 October 2005, $M_{\mathrm{w}} 7.6$ Kashmir, Pakistan, earthquake, has caused numerous casualties and severe damage to the infrastructures and changes to the landscape. The earthquake area is affected by logistic and security problems, thus, making the accessibility difficult for detailed field investigations. Indeed, this earthquake and its surface effects have been investigated earlier by different authors using satellite images.

Previous works are based on the use of Earth Observation (EO) data and on the visual inspection approach obtaining significant results for the recognition of the main surface effects (so as damage to infrastructures, landslides and surface cracks) associated to the 8 October 2005 Pakistan earthquake. Vinod et al. (2006) used Resourcesat-1 data (5.8 $\mathrm{m}$ resolution) and Cartosat-1 panchromatic stereoscopic data $(2.5 \mathrm{~m}$ resolution) to provide an overview of the damage to buildings and infrastructures in Uri region of Jammu and Kashmir, India, based on visual inspection procedures. The landslides triggered by the earthquake were studied by Sato et al. (2007) who provide a map of 2424 landslides identified by SPOT-5 images at $2.5 \mathrm{~m}$ pixel size (over an area of 55 by $51 \mathrm{~km}$ ). Lin and Guo (2008) have used QuickBird panchromatic data of the Muzaffarabad area inferring that co-seismic surface ruptures are mostly concentrated on pre-existing active faults striking NW-SE. They have identified surface cracks from several metres up to $1 \mathrm{~km}$ long, and large scale landslide mostly occurring in the uplift side of the faults.

In the present study, we have used panchromatic Quickbird imagery $(0.6 \mathrm{~m}$ spatial resolution) for detecting the three main co-seismic surface features, i.e., ruptures, damages and landslides, occurred in and around the Muzaffarabad and

Published by Copernicus Publications on behalf of the European Geosciences Union. 
Balakot towns. For each of the features different inspection methods, visual and automatic, have been tested. Automatic procedures have been used to capture damages (Chini et al., 2009) and landslides. For the latter, in particular, a new automatic method using only the post-earthquake image has been applied for landslide inventory and outlining. The outcomes from the two methods (visual and automatic) were compared with each other and with field survey data (i.e. Kaneda et al., 2008 and reference therein; Sato et al., 2007; The US National Academies Reconstruction Assistance Team, 2006; Khattak et al., 2010). Finally, the usefulness of the VHR satellite images in the detection of ruptures, landslide and damage has been discussed.

\section{Identification of earthquake surface features by optical satellite images}

In the following, we briefly summarize the most recent papers on the analysis of earthquake features using satellite images.

Changes in Synthetic Aperture Radar (SAR) backscattering and phase have been successfully exploited for earthquake damage mapping, combining image intensity changes and the related correlation coefficient (Matsuoka and Yamazaki, 2002, 2004; Yonezawa and Takeuchi, 2001; Stramondo et al., 2006; Chini et al., 2008b). The use of VHR resolution optical images is still principally related to visual inspection methods for preparing a realistic and reliable inventory of damage (i.e. Saito et al., 2004; Yamazaki et al., 2004) and for surface ruptures mapping (Klinger et al., 2005; Klinger et al., 2006).

The detecting and monitoring of landslides and their activity is of great relevance for disaster prevention, preparedness and mitigation in hilly areas. Nowadays, VHR satellite panchromatic imagery from Quickbird $(0.6 \mathrm{~m})$ provides the opportunity for mapping landslides at a more accurate scale of details (one order magnitude higher). Previous works have been conducted using the $5.8 \mathrm{~m}$ resolution IRS1D (Gupta and Saha, 2001; Metternicht et al., 2005), or simulated Ikonos data (Hervàs et al., 2003). In the latter study $1 \mathrm{~m}$ resolution Ikonos data have been simulated by scanning multi-temporal aerial photographs to implement a semi-automated approach aiming at digital change detection for mapping slope deformation at scales of up to 1:10000. Also lower resolution sensors, i.e., $15 \mathrm{~m}$ Terra/Aster, have proved to be useful for identifying landslides of considerable size (minimum width $150 \mathrm{~m}$ ). The most exploited were the differences in the spectral signature by visual inspection of false colour composites of two different dates (Domakinis et al., 2008). Change detection techniques, coupled with threshold algorithms, have been applied to multi-temporal digital aerial photographs simulating VHR optical imagery (Rosin and Hervàs, 2005). Supervised and unsupervised classifiers have been applied for mapping landslides, exploiting multi-spectral and multi-temporal information from $10 \mathrm{~m}$ resolution imagery (Borghuis et al., 2007). A supervised change detection exercise, using Landsat-TM by Tarantino et al. (2004), showed that the $30 \mathrm{~m}$ resolution data is able to provide information about the temporal trend of changes for macro surface classes, but are useless to monitor changes in artificial structures different from built-up areas, such as road networks. Multispectral Landsat-ETM (30 $\mathrm{m}$ of geometric resolution) data were also used for assessing the role of vegetation in mitigating landslides triggered by earthquakes (Peduzzi, 2010). The author stated also that for a local land planning, data with higher resolution are necessary, which is one of the issues of this paper. Four different classes of landslide susceptibility were also the outcome of an analysis carried out by Kamp et al. (2008) using ASTER data and GIS technology. Finally, Nichol and Wong (2005) highlighted that the multi-temporal and multi-spectral automatic or semiautomatic change detection methods are fruitful when applied to high resolution satellite images, whereas the visual inspection method remained the most suitable when using the VHR data.

\section{The Kashmir-Pakistan earthquake}

The 8 October 2005, $M_{\mathrm{w}} 7.6$ Kashmir, Pakistan, earthquake, was generated primarily by thrust motion on a NE-dipping fault, accompanied by minor right-lateral offset. The earthquake originated $\sim 100 \mathrm{~km}$ to the northeast of Islamabad, at about $26 \mathrm{~km}$ of depth and propagated upward causing thousands of casualties and producing significant surface effects, such as ruptures, landslides and damages (i.e. The US National Academies Reconstruction Assistance Team, 2006). Among the historically known large seismic events, the latter has produced extensive surface rupture for the first time in this zone. A $\sim 75 \mathrm{~km}$ long, NW-SE trending fault formed at the ground surface from the town of Balakot to northwest of Bagh (Fig. 1), as interpreted from remote-sensing data (Avouac et al., 2006; Fujiwara et al., 2006; Pathier et al., 2006) and confirmed by on-site field survey (Kaneda et al., 2008; Tapponnier et al., 2006; Yeats and Hussain, 2006). The earthquake rupture, known as Balakot-Bagh, was complex, generally not continuous and for most of its length followed the trace of pre-existing late Quaternary active faults (e.g. Nakata et al., 1991; Nakata and Kumahara, 2006).

Numerous large and small landslides, rockslides, rockfalls and debris flows were triggered by this earthquake (Sato et al., 2007; Dunning et al., 2007), both in bedrock and superficial Quaternary deposits.

The towns of Muzaffarabad and Balakot were crossed by the central-northern portion of the surface rupture and strongly suffered the occurrence of a large number of slope failures, causing massive destruction and severe damage to buildings, roads and bridges. The damage is dramatically higher along the fault rupture, concentrated on the hangingwall side (Kaneda et al., 2008). QuickBird imagery captured a clear image of these two urban areas and their surrounding 


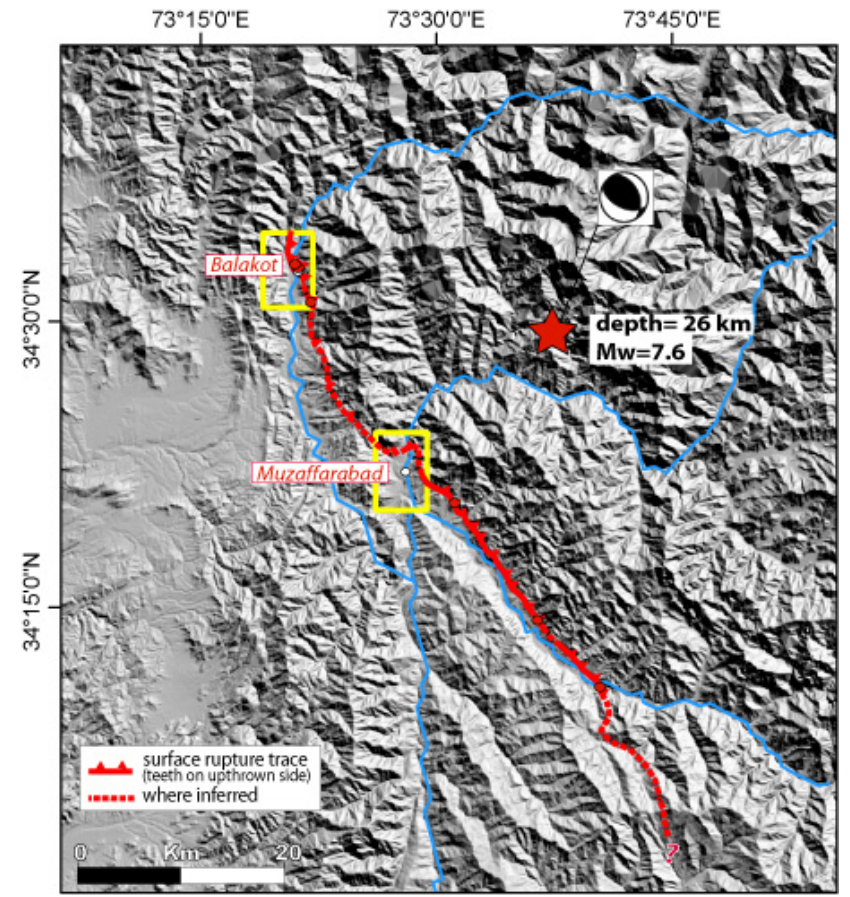

Fig. 1. The Balakot-Bagh surface fault rupture (red line from Kaneda et al., 2008). Yellow rectangles include the Muzaffarabad and Balakot areas of the analysed VHR images. USGS Location (http://neic.usgs.gov) and Harvard CMT solution of the earthquake (www.seismology.harvard.edu/CMTsearch) are shown.

rural regions after the 8 October 2005 earthquake (Fig. 2) and we used the images to examine most of the earthquake features that devastated the landscape.

\section{QuickBird imagery dataset}

QuickBird (owned and operated by DigitalGlobe) collects images at high degree of detail ( $0.6 \mathrm{~m}$ pixel resolution), the highest resolution available from satellite data at the time of the earthquake (nowadays GeoEye- 1 reaches $0.5 \mathrm{~m}$ ). This satellite, here applied to earthquake studies, is an excellent source of environmental data useful for analyses of changes in land usage, agricultural and forest climates. Our dataset is composed of two pairs of panchromatic QuickBird imagery taken before and after the event and centred on the Muzaffarabad and Balakot towns (Fig. 2), although data from multi-spectral QuickBird sensor with geometric resolution four times lower $(2.4 \mathrm{~m})$ were also available. These lower resolution images would have resulted in spatial information content of 16 times less. In Table 1 are summarized the characteristics of the imagery used in our analysis.

The post-event images of Muzaffarabad and Balakot areas are both taken less than 20 days after the disaster, best capturing the effects of the earthquake on the landscape/landform. However, the images before and after the event are taken in
Table 1. Pancromatic quickbird image ( $0.6 \mathrm{~m}$ spatial resolution).

\begin{tabular}{lcc}
\hline Muzaffarabad & Before event & After event \\
\hline Date & 13 Aug 2004 & 22 Oct 2005 \\
In-track angle & $7.7^{\circ}$ & $-7.6^{\circ}$ \\
Cross-track angle & $6^{\circ}$ & $22.4^{\circ}$ \\
Off-nadir angle & $9.7^{\circ}$ & $23.6^{\circ}$ \\
Sun elevation angle & $63.3^{\circ}$ & $43.2^{\circ}$ \\
Sun azimuth angle & $132.4^{\circ}$ & $163.1^{\circ}$ \\
Pass time (UTC) & $05: 50$ & $06: 00$ \\
Covered area (km ${ }^{2}$ ) & 23.4 & 30.9 \\
\hline Balakot & Before event & After event \\
\hline Date & 11 Aug 2005 & 19 Oct 2005 \\
In-track angle & $1.7^{\circ}$ & $10.8^{\circ}$ \\
Cross-track angle & $27.9^{\circ}$ & $17.1^{\circ}$ \\
Off-nadir angle & $28^{\circ}$ & $20.2^{\circ}$ \\
Sun elevation angle & $64.5^{\circ}$ & $44.8^{\circ}$ \\
Sun azimuth angle & $134^{\circ}$ & $167.5^{\circ}$ \\
Pass time (UTC) & $05: 56$ & $06: 15$ \\
Covered area (km ${ }^{2}$ ) & 30.8 & 30.8 \\
\hline
\end{tabular}

different seasons, rainy and cool, respectively, thus, making it difficult for the direct comparison due to different solar illumination (i.e. different shadow, different tree foliation, grass colour). The time interval between the acquisitions of the images is less than 3 months on Balakot and a longer interval of about one year for the Muzaffarabad area. Moreover, the available images differ in the view angles (along and across track) over $10^{\circ}$, causing a relative geometric distortion of objects at the surface.

In this study, we have focused on three different features of earthquake, calling for different scales of detail. In particular, the detection of infrastructure damages and surface fractures absolutely requires the highest available spatial resolution images. While smaller resolution and, thus, smaller scale of detail could still provide exhaustive information of the landslides phenomena.

\section{Methodology}

Change detection is an important process in many remotesensing applications, such as monitoring urban development and assessing damages caused by natural disasters. Usually we have two co-registered images of the same scene captured at different times and aiming to detect the changes which occurred in the scene at that time interval. The result of the change detection process is a binary image (called change map or change image). The most straightforward approach to change detection is image subtraction, where the two co-registered images are simply subtracted by each other (by an algorithm and or by an interpreter). Then, the 

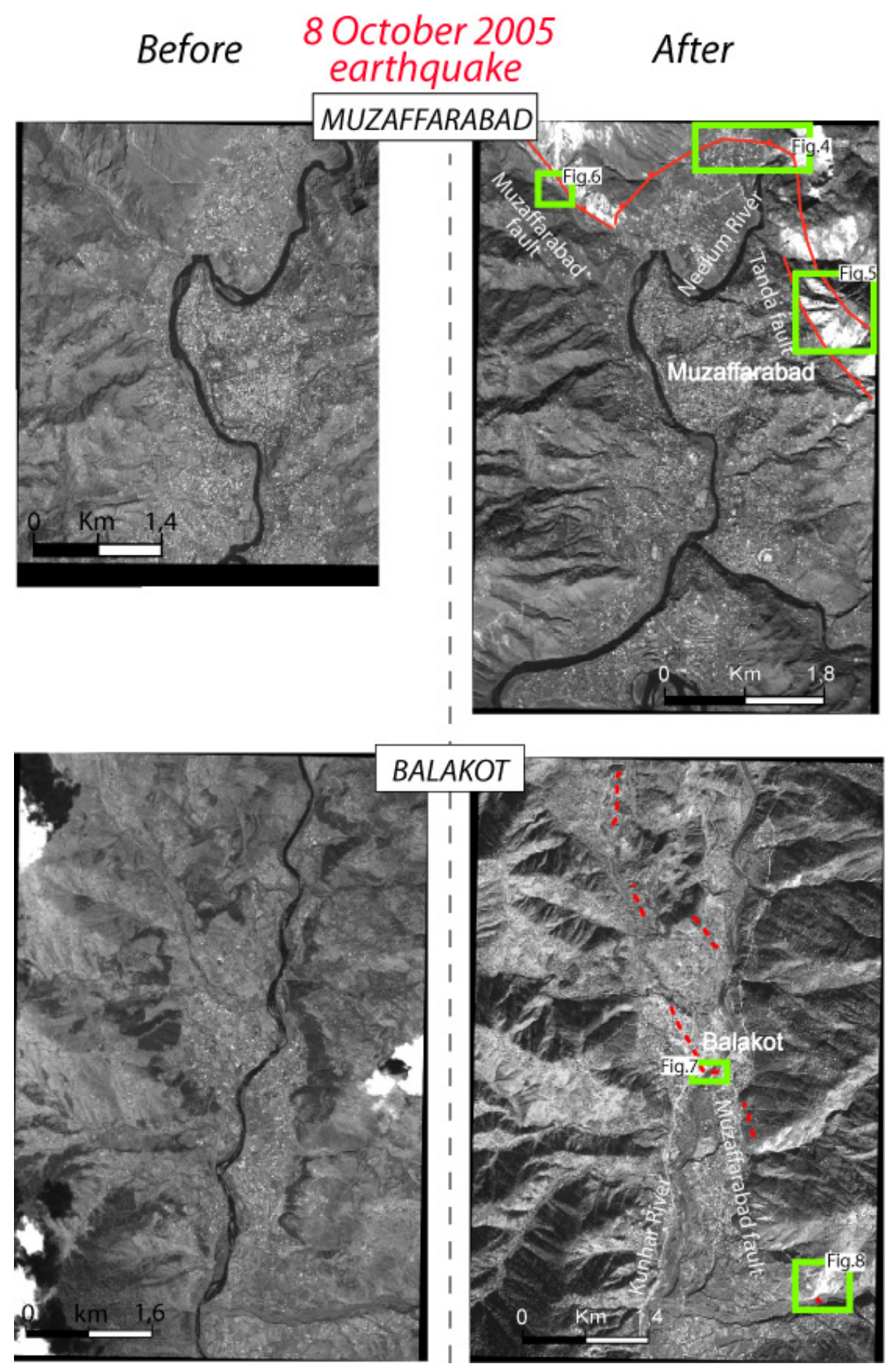

Fig. 2. Quickbird images acquired before and after the 8 October 2005 earthquake for both areas of Muzaffarabad (13 August 2004 and 22 October 2005) and Balakot (11 August 2005 and 19 October 2005). Fault trace is marked with red line, dashed where inferred. The green rectangles include the areas shown in the indicated figures.

pixels with difference values greater than a predetermined threshold are identified as changed pixels. Therefore, a variety of change detection algorithms have been introduced in the literature, such as the Post-Classification Comparison (PCC) (Serra et al., 2004), the direct Multi-Data Classifica- tion (DMC) (Sunar Erbek et al., 2004) and parallel architecture with the aim to combine previous approaches for exploiting the multi-spectral and multi-temporal characteristics (Chini et al., 2008c; Pacifici et al., 2007). 
While the change detection technique remains a reliable tool, both the visual and the automatic approaches are affected by error sources, especially using VHR sensors. Indeed, the two images can be acquired in different seasons, thus, having different solar illuminations causing a variation in shadow effects, different vegetation, a variation in radiance values, ground water content and so on. In addition, temporary objects present in the scene and differences in the looking angle represent another source of errors to take into account.

\subsection{Visual inspection}

We have delineated the distribution of surface ruptures, landslides and damages in and around Muzaffarabad and Balakot by comparing panchromatic QuickBird images taken before and after the earthquake.

Many of the surface ruptures are very small (under the pixel-size), but wherever significant, they are expressed by thin, darker lines in the ground, associated with shadow and fresh soil filling. As we show in Sect. 6.1, the projection of shadow on the ground can be information to discriminate against the possible relative vertical motion of the two sides across the rupture. Clear pattern can be reconstructed in detail. The large scarps generally appear as light grey in relative to the surrounding colour. Landslides were diffused and are clearly identified as bright, white slopes, both because of the removal of vegetation and fresh rock surface exposed. In these images, damaged buildings appear always in light grey, lighter is the high level of destruction (rubbles). Bridges, as well as roads, partially collapsed and are distinguishable on the images. Changes of the stream course, new formation or the increase of waterfalls are other evidences of changes in the landscape that were detectable by comparing the images.

In order to verify and validate our interpretation of the features, we used the ground truth data from several Authors (i.e. Kaneda et al., 2008 and reference therein).

\subsection{Automatic classification}

In the following, we describe the automatic procedures used for the damage and the landslide detection aiming to provide final maps at the same resolution of the original panchromatic images.

Concerning the damage detection, in order to overcome the sources of errors due to differences between the preand post images mentioned at the beginning of the section, we have preliminarily classified the pre-seismic image with the aim to extract the building map and, later on, we computed change detection only for those pixels referred to them. This allowed removing most of the change detection false alarms (e.g. scene changes not related to the earthquake features) mainly due to shadows, cars and variable vegetated areas.
The extraction of the building map is not possible using a single panchromatic image, since many objects can be wrongly associated in the same class having similar radiance values (e.g., cars vs. buildings, shadow vs. some asphalt roads, soil vs. some kinds of roofs) (Fauvel et al., 2006; Zhong and Wang, 2007). Consequently, it clearly appears to need additional attributes to characterise and to distinguish objects from each other. Due to the lack of multi-spectral data with $0.6 \mathrm{~m}$ spatial resolution, morphological features were useful for extracting object attributes related to their dimensions and geometry (Benediktsson et al., 2005; Pesaresi and Benediktsson, 2001) besides textural parameters (Pacifici et al., 2009).

Moreover, the peculiar signature of some sources of change detection artifacts are not of spectral type (for instance, a car may have any kind of colour) but can be associated to specific shapes (for instance, a car has essentially a rectangular shape) and size. For this reason, the mathematical morphology is a powerful tool to overcome this kind of classification problems.

Two important operators, erosion and dilation, are at the base of mathematical morphology (Soille, 2003). They are applied to images using a Structuring Element (SE) of known shape, corresponding to specific geometrical figures, to see how structures, in the image, match those specific elements. The output of the erosion operator is an image showing those structures in the input image fitting the SE. On the other hand, the output of the dilation operator shows where the SE hits the objects in the image. These two operators, at the basis of mathematical morphology, are dual but non-invertible. All other morphological operators are a combination of erosion and dilation. Among them are the opening and closing operators. Opening dilates and erodes an image in order to recover as much as possible of the original image. On the contrary, closing dilates and erodes an image with the aim to recover the initial shape of image. The main property of the filtering process provided by the opening and closing operators is that not all structures within the original image are recovered when these operators are subsequently applied. In fact, these two operators are used for isolating bright (opening) and dark (closing) structures in the image. For bright and dark we mean brighter and darker with respect to other neighbouring structures. Moreover, the size of the SE, with respect to the size of the structures in the images, addresses the output of the filtering operation to have a response lead by the size. This particular characteristic, used in a multi-scale approach (Benediktsson et al., 2005), makes the mathematical morphology a powerful instrument for classifying object by their shape and size.

Accordingly, the creation of a building map has been obtained in two steps. First, by means of opened and closed morphological filters (Soille, 2003) with different window sizes $(3 \times 3 / 41 \times 41$, stepping two pixels) (Fig. 3a), a morphological profile has been created based on the original panchromatic image, accounting for the geometric 
characteristics of objects. Second, the morphological profile previously extracted, plus the panchromatic image, were the input to an unsupervised Isodata classifier (Richards, 1986) to obtain the mask of the built-up areas (the building mask) (Fig. 3b).

The damage map has been obtained by a threshold algorithm applied to the normalized difference between pre-and post-panchromatic images extended to the built-up area only (Chini et al., 2009). To perform this kind of algorithm the pixel level co-registration is necessary, since the classification is pixel-based and provides a damage map with the same resolution of the panchromatic image $(0.6 \mathrm{~m})$. The accurate co-registration is reached not only through the orthorectification of the images, but also by a selection of tie points between images. In the case of the 2005 Pakistan earthquake, the looking angle between the two acquisitions were very different (see Table 1), but this did not prevent the identification of damaged buildings because the town of Muzaffarabad and Balakot extent in quite flat areas.

Instead, a new land cover classification method different from the above-mentioned change detection approach is applied to landslide mapping. The classic change detection method cannot be applied to investigate the landslide phenomenon which usually occurs on very steep regions, because an accurate co-registration is not possible when large differences are in the acquisition look angle of the satellite. Since we did not want to degrade the resolution of the final product, we have moved toward a land use classification approach for identifying the landslides, using only one postevent image, plus its morphological profile. This has been possible because the landslide area has different radiance values with respect to the surrounding pixels, and different extension and geometry with respect to other classes within the scene. All these characteristics can be extracted using contextual multi-scale approaches. This classification method is similar to that used for the buildings classification (Fig. 3b), thus, all the considerations above are still valid. We are aware of the fact that using only one post-event image the multitemporal information is not exploited (Pacifici et al., 2007; Chini et al., 2008c). On the other hand, the normalization to compensate for atmospheric conditions and sensor differences between the acquisition dates is not required, and also the co-registration step is overcome, thereby reducing the frequent problems associated to it.

\section{Results}

A general outcome from our work is that for co-seismic surface effects assessment, the time acquisition of the postseismic imagery is critical and may affect the analysis of all the features, damages, landslides and surface breaks. The post-seismic dataset used in the Pakistan case study is very close to the event (less than 2 weeks after), this allows us to reasonably affirm that the landscape changes observed, including the damages, are related to the seismic shaking.
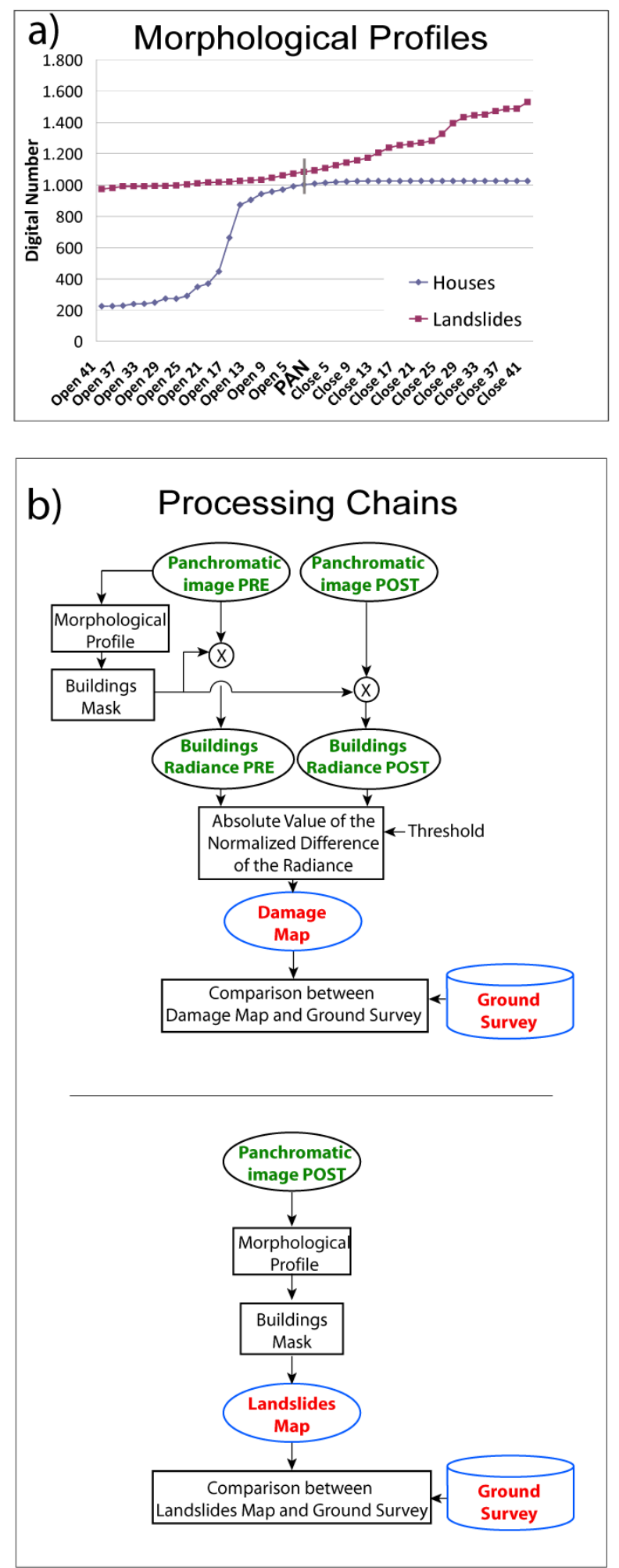

Fig. 3. (a) Morphological profiles of two classes of interest: Houses (blue) and Landslides (red). The vertical gray line in the middle indicates the panchromatic original image. Close to this line are small windows of morphological filters. The left part shows the output of the open operator, while the right part shows the close operator. (b) Processing Chains of the automatic algorithm for mapping damages (up) and landslides (down). 
Moreover, some considerations come out concerning the temporal resolution of the images. We have observed that the urban settlement in the images before and after the event is different, since the urban area considerably developed within the time interval of two images, particularly in the Muzaffarabad urban zone. A significant number of new buildings (with respect to the pre-event image available) are present in the post-event image and also the dimensions of some structures have changed. This change of the urban texture prejudices the correct quantitative analysis of the infrastructures and, in other words, the damage map presumably underestimates the amount of partial or total collapses.

\subsection{Surface ruptures and scarps}

The surface ruptures produced by the 2005 Pakistan earthquake generally have a size below the Quickbird resolution $(0.6 \mathrm{~m}$ pixel size $)$. Keeping this view we proceed with the visual identification of such features by comparing the preand post-images of both the Muzaffarabad and Balakot areas. In both areas, the fault trace is prominent for several kilometres, particularly wherever the fresh white surface of the dolomitic limestone has been exposed on the upthrown northeast side of the fault plane. In general, we have observed that the newly-formed co-seismic scarps occurred where sharp topographic changes already existed. This suggests that the present day topography is a result of repeated fault movements over time. Among the surface ruptures recognized, we cite only the most significant and clearly detectable ones. The area of Muzaffarabad was crossed by an E-W trending scarp (Fig. 4), interpreted as a lateral ramp connecting the left-stepping main thrust fault (Fig. 1). The scarp is south facing and has a maximum vertical separation of $2.45 \pm 0.25 \mathrm{~m}$ (Kaneda et al., 2008). Even though we could not estimate such scarp heights, in the post-event image it is evident the sunshade projection which allows us to discriminate the uplifted side. It is also impressive to see the change of the Neelum River course induced by the triggered landslides on the eastern flank and by the surface rupture. A zone of linear deformation expressed by multiple ruptures has been recognized along the slope south-east of the urban area of Muzaffarabad (Fig. 5d). The complex enechelon geometric patterns of these co-seismic ruptures are clearly delineated. Even though the features occur at the top of an extended landsliding area, they represent surface faulting as they are located in correspondence to the earthquake fault (as traced by Lin and Guo, 2008) and have a constant direction. Some considerations on the style of deformation of these ruptures can be inferred from sunshade effects. In fact, from sunlight view of the images (quite orthogonal to the ruptures, sun rays from south) the shadow produced by the newly formed southwest-facing portion of uplifted ground in case of vertical component (northeast uplifted side), is absent or not so evident on the ground. Thus, we exclude a significant vertical motion along these ruptures and the darkness/shadow detected reasonably represents only the contribution of the opening and/or small horizontal relative movements. Figure $6 \mathrm{~b}$ shows the area westward the Muzaffarabad town, where the surface faulting cuts across a river valley (Jhlim Kashmir River). The scarp trace is clear, so as the flooding area within the river valley in the downthrown side of the scarp. It is worthy to note that a right-lateral sense of motion along the fault at this site may be inferred from the deviation of the river and from the displaced edge of the road close to the valley.

The surface breaks in the Balakot section were difficult to recognize, since most of their extent occur within the urbanized area and are spread below the rubbles, so that such features are mostly masked. Figure $7 \mathrm{~b}$ reveals surface faulting and associated damages on both edges of the Kunhar River valley. The scarp prosecution below the water is testified by the new formation of a water fall and to the north by the large displacement affecting the road. As a general consideration, the remote survey was partial within intensively urbanized areas; on the other hand it allowed the visible access to areas unreachable for the field surveyors both for high reliefs and landscape disruptions, and political problems.

\subsection{Damages}

In order to analyse the damages which occurred on buildings, we have applied the automatic technique as described in Sect. 5.2. The huge difference between the look angle of the satellite, pre- and post-acquisition, and the strong relief characterising the earthquake area permit to apply the procedure only for sufficiently flat regions in the image.

We note two type of urban textures, dense and discontinuous. Both these types of urbanization are present in Muzaffarabad and Balakot, although the latter records a denser concentration of buildings in the fault area. Structural damages were especially severe in the town of Balakot and in the northern portion of Muzaffarabad. The description of the building typologies and damage scale are reported in Rossetto and Peiris (2009). In general, we have observed that major damages occur on and close to the hanging-wall side of the thrust surface rupture, as an effect of extensive ground failure for faulting and strong shaking (The US National Academies Reconstruction Assistance Team, 2006). Using the automatic procedure in Sect. 5.2, in Muzaffarabad we analysed the relation damage/fault zone quantifying the failures occurred in the area. As a result, we show the damage distribution in Fig. 4c. A $\sim 70 \mathrm{~m}$ wide zone of strong destruction is measured across the fault trace. The map certainly underestimates the amount of damage since it takes into account the buildings in the pre-event image (see discussion at the beginning of this section). Based on the number of pixels recognized as buildings in the pre-event image, and the amount of them recognized as damaged by the procedure, 

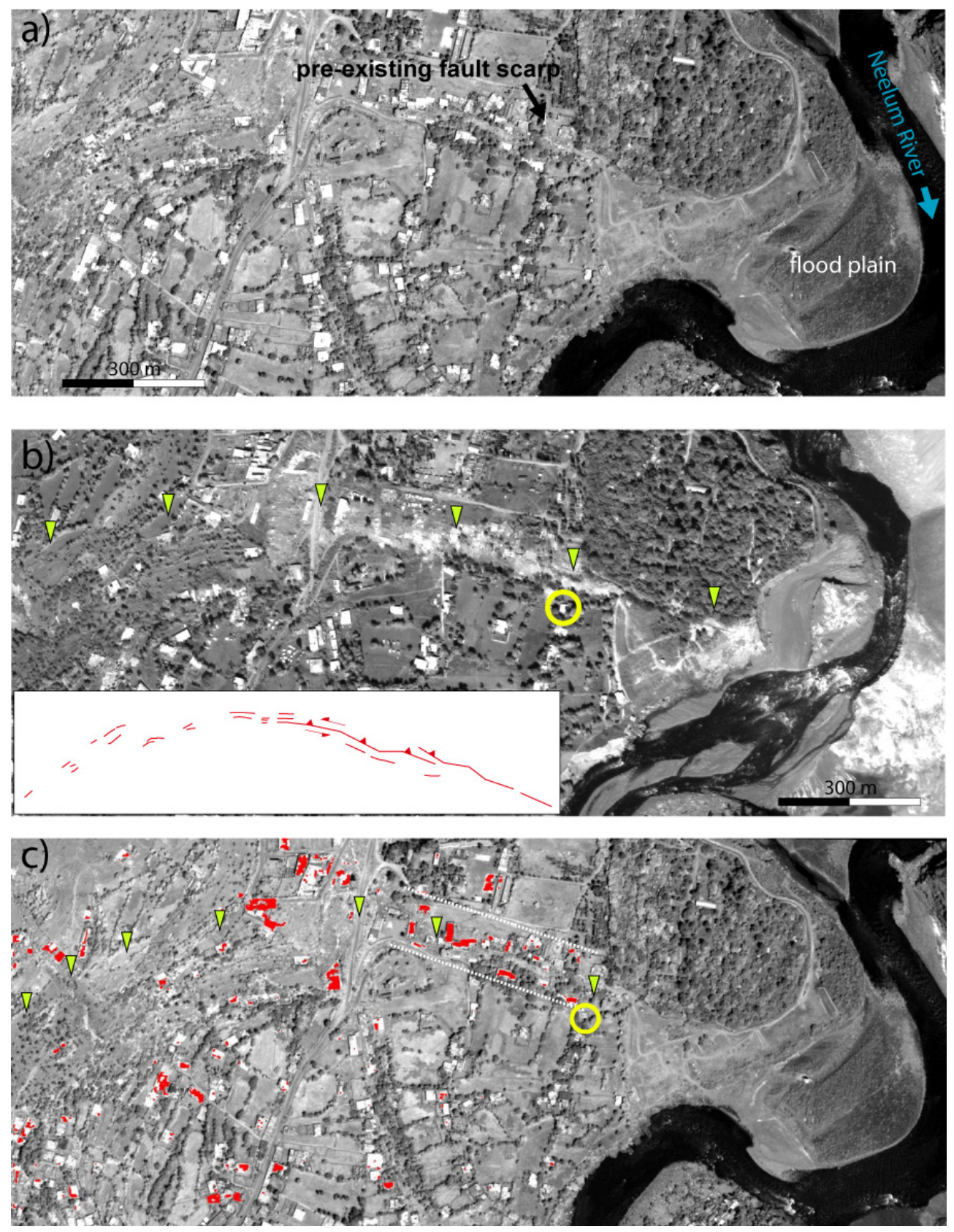

Fig. 4. Detail of the northernmost area of Muzaffarabad. (a) Pre-event image (13 August 2004); (b) post-event image (22 October 2005); green triangles point the main surface rupture. The sketch on left side shows the E-W trending scarp: lateral ramp connecting the left-stepping main thrust fault, $2.45 \pm 0.25 \mathrm{~m}$ (max vertical separation), $\sim 4.6 \mathrm{~m}$ horizontal shortening and $\sim 0.6 \mathrm{~m}$ left lateral. Refer to (c) for yellow ring symbol; c) damaged houses automatically detected (in red) superimposed on the pre-event image. Intense damaging occurs within the white dashed lines along the fault scarp. Based on our procedure, the building encircled by the yellow ring is undamaged. The same not strongly damaged building, out of the intense damaged zone, and the fault scarp are shown in Fig. 5 of Lin and Guo (2008) being depicted by the Authors through a field survey.

we may quantify the damaging relative to the fault position. We estimate a larger percentage of damaged pixels in the uplifted block of the fault scarp (42\%) with respect to that in the subsided side $(22 \%)$.

\subsection{Landslides}

We have mapped the landslides distribution using VHR panchromatic images from QuickBird satellite mission. Coseismic landslides of different sizes, which are mostly spatially associated to the fault and concentrated on the uplifted 

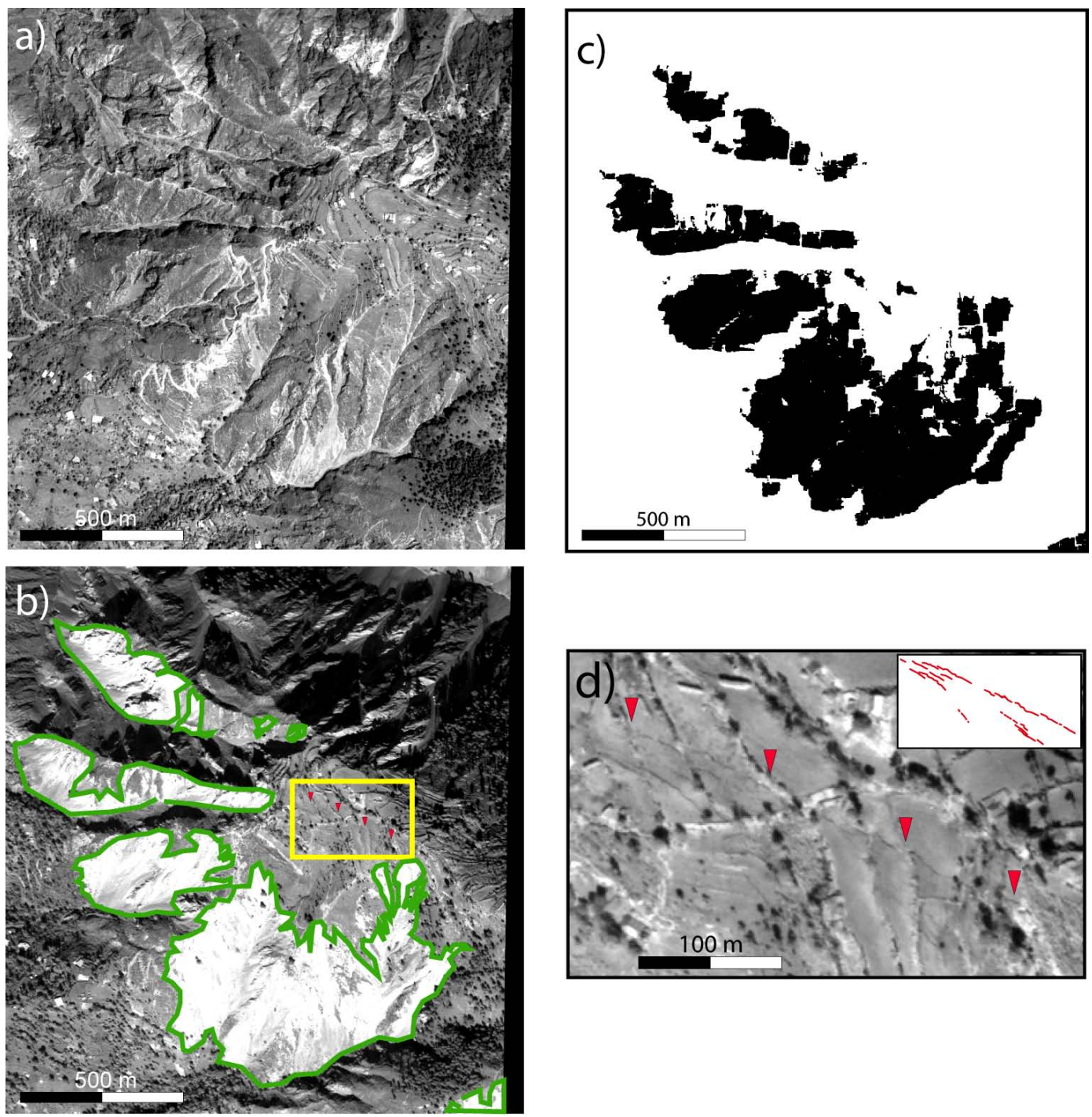

Fig. 5. (a) Pre-event image (13 August 2004) centred on the slope east of Muzaffarabad; (b) post-event image (22 October 2005) of the same area where surface breaks are marked by red triangles and landslides areas are contoured with a green line by visual inspection. Yellow rectangle is the area shown in the detail of inset (d). (c) Landslides (black areas) occurring in the area detected by the automatic classification; (d) detailed view and sketch of the surface breaks (0.6-1 m width of linear deformation).

block, have been identified. This spatial setting would suggest that large scale landslides have been directly triggered by the movement along the fault. Moreover, by the visual inspection of the pre-event image, many of the 2005 earthquake landslides occur where long-term gravitational slope deformation and/or old crowns on the slope already existed. Since the visual procedure is time consuming, we have applied the automatic classification. The output maps are shown in Fig. 9. The accuracy obtained for the landslide shape and the scale of details of the features mapped straight emerges in Figs. 5, 6 and 8. Moreover, it is worth noting that the classification procedure has been applied to the entire images (Balakot: 86018464 pixels; Muzaffarabad: 86001904 pixels), and the obtained results, show in Figs. 5, 6 and 8, prove the reliability of this procedure in an operational task. In fact, the landslide areas and their pattern appear well identified and correctly geolocated and the differences between visual inspection and automatic classification are trivial.

\section{Concluding remarks and discussion}

We have observed that VHR satellite data provided a synoptic view of the landscape and made possible the automatic monitoring of the changes with respect to time. The automatic classification techniques gave reliable results, as addressed to the identification of damaged manufacts and landslides at pixel scale. While the visual inspection was required 

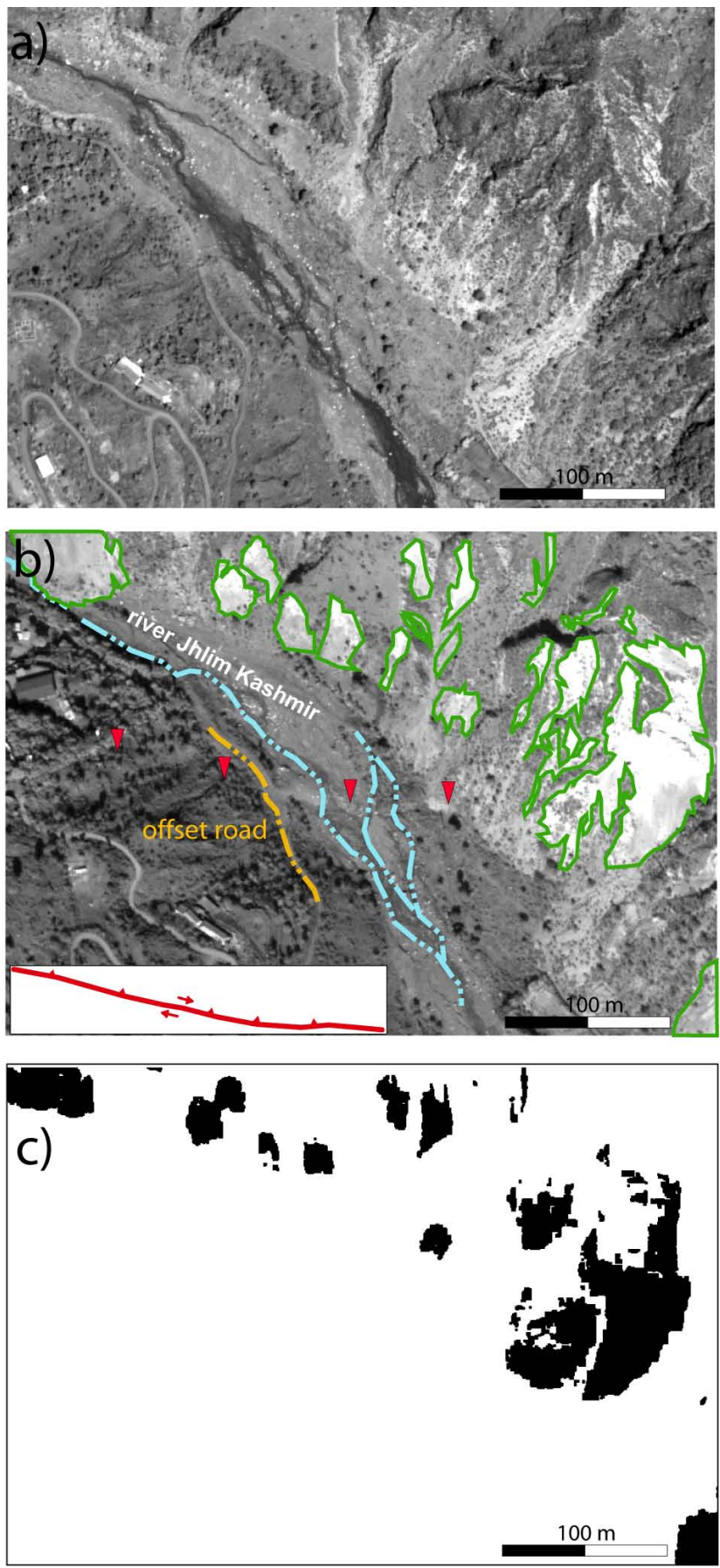

Fig. 6. (a) Pre-image (13 August 2004) of the area across the Jhlim Kashmir river. (b) Post-event image (22 October 2005) of the same area. Surface rupture (red triangles) and landslides (contoured by green line) are mapped by visual inspection. Road and stream offsets across the rupture trace is also indicated (see text for discussion). On left corner is a sketch of the fault scarp $(2.45 \pm 0.25 \mathrm{~m}$ (av. vertical separation). (c) Landslides (black areas) occurring in the area detected by the automatic classification.
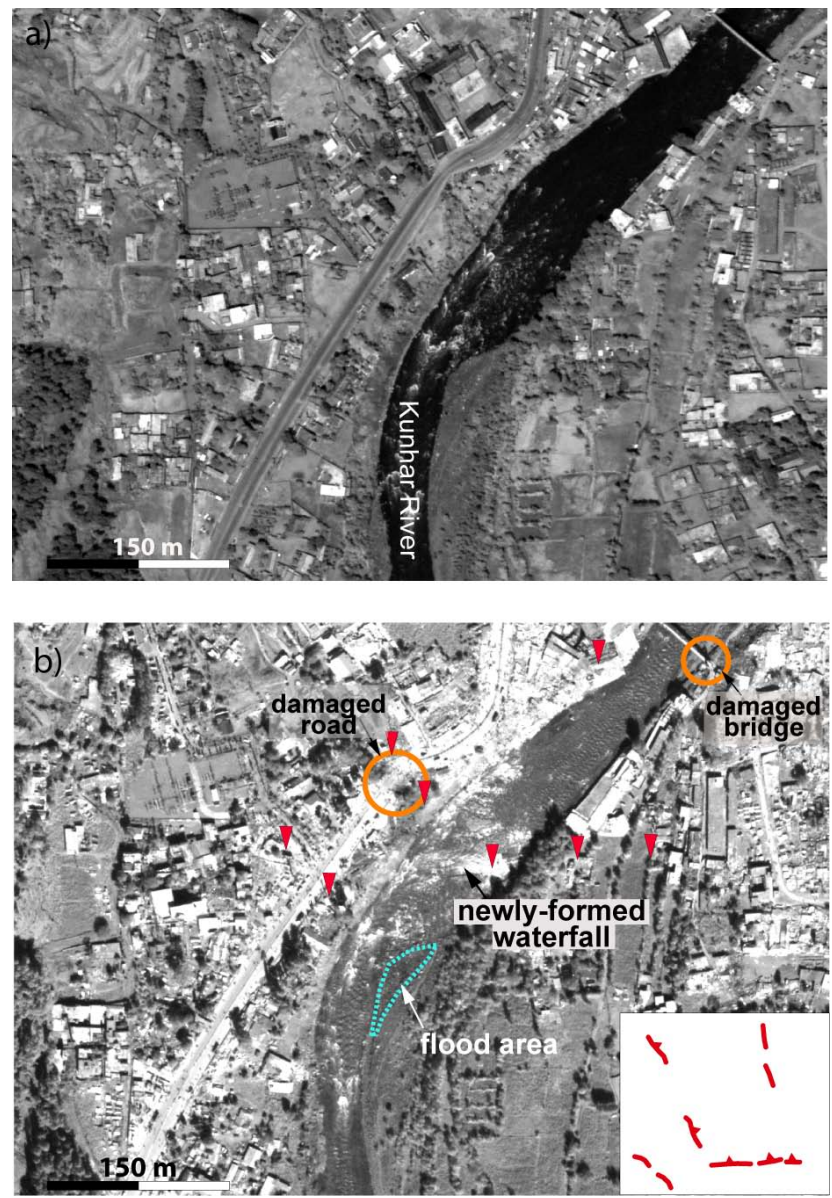

Fig. 7. (a) Pre-event image (11 August 2005) centred on downtown Balakot. (b) Post-event image (19 October 2005) of the same area. Surface traces are pointed (red triangles), as well as significant damaged and coseismic changes within the river course. The inset shows the pattern of the traces in detail (S-facing monocline, $1.45 \pm 0.15 \mathrm{~m}$ of vertical separation).

for detecting the fault rupture strands and associated features, it was more difficult to recognize because of it being generally lower than pixel size. Thus, combining the results from visual inspection and automatic classification, we obtained a frame of ground co-seismic effects produced by the earthquake. Such effects can be severe and provoke lots of human tragedies, other than representing a tremendous economic loss and inconvenience by infrastructure destruction, particularly inhibiting the movement of aid into the disaster area.

The capability of VHR images shown in the Pakistan case study for detecting the surface faulting, the locations of landslides and damages, allow to affirm that this mixed methodology of investigations plays an important role both for near real-time estimation of coseismic effects (main issues to promptly respond in a struck territory) and for seismic hazard 

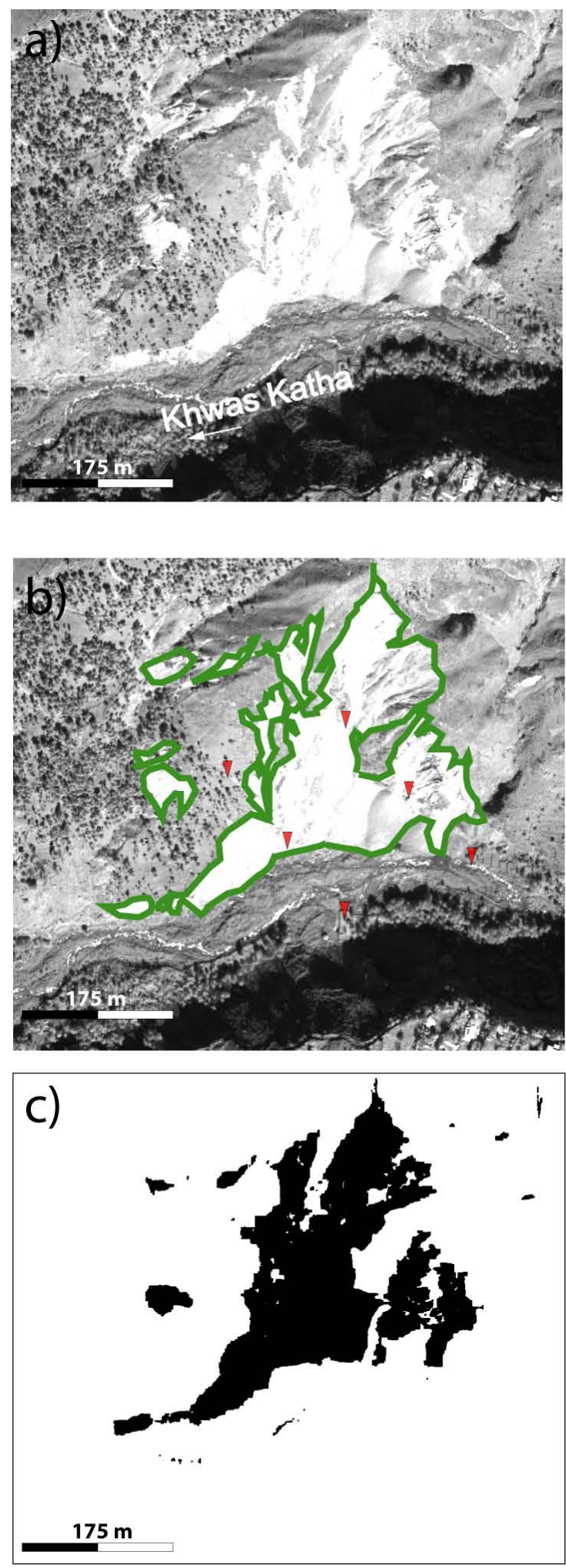

Fig. 8. (a) Pre-event image (11 August 2005) of an area on the south-eastern slope of Balakot (Khwas Katha). (b) Post-event image (19 October 2005) of the same area where a large landslide area is contoured by a green line as detected by visual inspection. Red triangles point to a possible deformed area. (c) Landslide (black area) occurring in the area detected by the automatic classification.
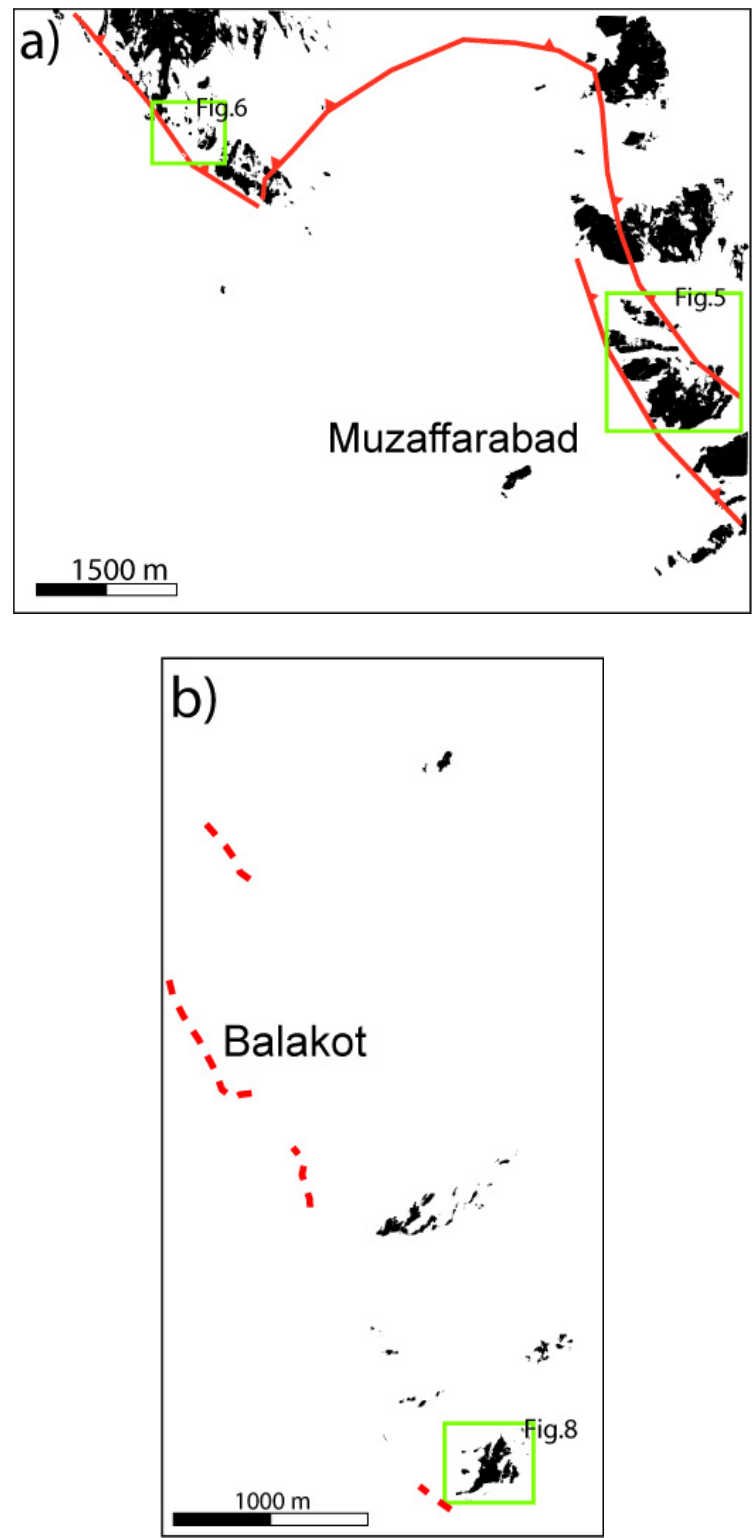

Fig. 9. Maps of the landslides (black areas) occurring in the whole area covered by the images, (a) Muzaffarabad, (b) Balakot, detected by the automatic classification. Green boxes include the landslides detail shown in Figs. 5, 6 and 8. The red line is the fault trace.

assessment. In fact, the analysis of the VHR optical images provide a timeliness knowledge of the nature, of the location and of the extension of natural disastrous phenomenon, especially in extended and unreachable areas where it results as useful for rescue teams both in the preparatory and recovery phase.

Concerning the surface faulting hazard the knowledge of the exact location for co-seismic rupture occurrence, style of deformation and fault trace is fundamental for risk mitigation, thus, also including facilities planning. Regarding 
the landslides detection, the temporal sampling of the slope failures induced by strong shaking, during and after a seismic crisis, allows the monitoring of the region and updates its hazard. It is worthy to note that the automatic procedure for mapping landslides in the present work have elaborated images with more than 80 million pixels each in few hours, not comparable with the amount of time needed for an expert operator for a visual inspection. Reliable damage maps provide information for macroseismic scenarios, for rupture process and site effects analysis, issues to take into account for hazard assessment.

Other than the recognition and classification of the coseismic effects, the quantitative analysis in terms of the amount of slip, volume involved in sliding, percentage analysis, are critical issues for seismic hazard evaluation. To these topics a small difference between the view acquisition angles of the pre- and post-VHR images, acquired close to the event, and detailed DEM are basic requirements. In summary, the peculiarities of satellite images (synoptic view and spatiotemporal sampling of the landscape) and the automatic change detection algorithms are able to reduce time needed to understand the phenomena and also play an important role in the evaluation of seismic hazard.

Acknowledgements. We would like to thank DigitalGlobe for providing data used in this research study. Marco Chini has been partially funded by the Italian Space Agency (ASI) through the SIGRIS project.

\section{Edited by: F. Guzzetti}

Reviewed by: two anonymous referees

\section{References}

Avouac, J. P., Ayoub, F., Leprince, S., Konca, O., and Helmberger, D. V.: The 2005, Mw 7.6 Kashmir earthquake: Sub-pixel correlation of ASTER images and seismic waveforms analysis, Earth Planet. Sci. Lett., 249, 514-528, 2006.

Benediktsson, J. A., Palmason, J. A., and Sveinsson, J. R.: Classification of hyperspectral data from urban areas based on extended morphological profiles, IEEE T. Geosci. Remote, 43, 480-491, 2005.

Borghuis, A. M., Chang, K., and Lee, H. Y.: Comparison between automated and manual mapping of typhoon triggered landslides from SPOT-5 imagery, Int. J. Remote Sens., 28, 1843-1856, 2007.

Chini, M., Bignami, C., Brunori, C., Atzori, S., Tolomei, C., Trasatti, E., Kyriakopoulos, C., Salvi, S., Stramondo, S., and Zoffoli, S.: The SIGRIS project: a remote sensing system for seismic risk management, Proc. IEEE IGARSS 2008, 3, 624627, 2008a.

Chini, M., Bignami, C., Stramondo, S., and Pierdicca, N.: Uplift and subsidence due to the December 26th, 2004, Indonesian earthquake and tsunami detected by SAR data, Int. J. Remote Sens., 29, 3891-3910, 2008b.
Chini, M., Pacifici, F., Emery, W. J., Pierdicca, N., and Del Frate, F.: Comparing Statistical and Neural Network Methods Applied to Very High Resolution Satellite Images Showing Changes in Man-Made Structures at Rocky Flats, IEEE T. Geosci. Remote, 46, 1812-1821, 2008c

Chini, M., Pierdicca, N., and Emery, W. J.: Exploiting SAR and VHR optical images to quantify damage caused by the 2003 Bam earthquake, IEEE T. Geosci. Remote, 47, 145-152, 2009.

Domakinis, C., Oikonomidis, D., and Astaras, T.: Landslide mapping in the coastal area between the Strymonic Gulf and Kavala (Macedonia, Greece) with the aid of remote sensing and geographical information systems, Int. J. Remote Sens., 29, 68936915, 2008.

Dunning, S. A., Mitchell, W. A., Rosser, N. J., and Petley, D. N.: The Hattian Bala rock avalanche and associated landslides triggered by the Kashmir Earthquake of 8 October 2005, Eng. Geol., 93, 130-144, 2007.

Fauvel, M., Chanussot, J., and Benediktsson, J. A.: Decision fusion for the classification of urban remote sensing images, IEEE T. Geosci. Remote, 44, 2828-2838, 2006.

Fujiwara, S., Tobita, M., Sato, H. P., Ozawa, S., Une, H., Koarai, M., Nakai, H., Fujiwara, M., Yarai, H., Nishimura, T., and Hayashi, F.: Satellite Data Give Snapshot of the 2005 Pakistan Earthquake, EOS T. Am. Geophys. Un., 87, 73-77, 2006.

Gupta, R. and Saha, A.: Mapping debris flows in the Himalayas, available at: http://www.gisdevelopment.net/application/nrm/ mountain/mounm0001.htm (last access: 10 November 2010), 2001.

Hervàs, J., Barredo, J., Rosin, P., Pasuto, A., Mantovani, F., and Silvano, S.: Monitoring landslides from optical remotely sensed imagery: The case story of Tessina landslide, Italy, Geomorphology, 54, 63-75, 2003.

Kaneda, H., Nakata, T., Tsutsumi, H., Kondo, H., Sugito, N., Awata, Y., Akhtar, S. S., Majid, A., Khattak, W., Awan, A. A., Yeats, R. S., Hussain, A., Ashraf, M., Wesnousky, S. G., and Kausar, A. B.: Surface Rupture of the 2005 Kashmir, Pakistan, Earthquake and Its Active Tectonic Implications, B. Seismol. Soc. Am., 98 , 521-557, 2008.

Kamp, U., Growley, B. J., Khattak, G. A., and Owen, L. A.: GISbased landslide susceptibility mapping for the 2005 Kashmir earthquake region, Geomorphology, 101, 631-642, 2008.

Khattak, G. A., Owen, L. A., Kamp, U., and Harp, E. L.: Evolution of earthquake-triggered landslides in the Kashmir Himalaya, northern Pakistan, Geomorphology, 115, 102-108, 2010.

Klinger, Y., Xu, X., Tapponnier, P., Van der Woerd, J., Lasserre, C., and King, G.: High-Resolution Satellite Imagery Mapping of the Surface Rupture and Slip Distribution of the Mw 7.8, 14 November 2001 Kokoxili Earthquake, Kunlun Fault, Northern Tibet, China, B. Seismol. Soc. Am., 95(5), 1970-1987, 2005.

Klinger, Y., Michel, R., and King G.: Evidence for an earthquake barrier model from Mw 7.8 Kokoxili (Tibet) earthquake slipdistribution, Earth Planet. Sc. Lett., 242, 354-364, 2006.

Lin, A. and Guo, J.: Co-seismic surface ruptures produced by the 2005 Pakistan Mw7.6 earthquake in the Muzaffarabad area, revealed by QuickBird imagery data, Int. J. Remote Sens., 29, 235 246, 2008.

Matsuoka, M. and Yamazaki, F.: Application of the damage detection method using SAR intensity images to recent earthquakes, Proc. IEEE IGARSS 2002, 4, 2042-2044, 2002. 
Matsuoka, M. and Yamazaki, F.: Use of satellite SAR intensity imagery for detecting building areas damaged due to earthquakes, Earthq. Spectra, 20, 975-994, 2004.

Metternicht, G., Hurni, L., and Gogu, R.: Remote sensing of landslides: An analysis of the potential contribution to geo-spatial systems for hazard assessment in mountainous environments, Remote Sens. Environ., 98, 284-303, 2005.

Nakata, T. and Kumahara, Y.: Active faults of Pakistan with reference to the active faults in the source of the 2005 north Pakistan earthquake, Geological Survey of Pakistan, Islamabad, Pakistan, 18-20, 2006.

Nakata, T., Tsutsumi, H., Khan, S. H., and Lawrence, R. D.: Active Faults of Pakistan, Research Center for Regional Geography Hiroshima University, Hiroshima, Japan, 141 pp., 1991.

Nichol, J. and Wong, M. S.: Satellite remote sensing for detailed landslide inventories using change detection and image fusion, Int. J. Remote Sens., 26, 1913-1926, 2005.

Pacifici, F., Del Frate, F., Solimini, C., and Emery, W. J.: An innovative neural-net method to detect temporal changes in highresolution optical satellite imagery, IEEE T. Geosci. Remote, 45, 2940-2952, 2007.

Pacifici, F., Chini, M., and Emery, W. J.: A neural network approach using multi-scale textural metrics from very high resolution panchromatic imagery for urban land-use classification, Remote Sens. Environ., 113, 1276-1292, 2009.

Pathier, E., Fielding, E. J., Wright, T. J., Walker, R., Parsons, B. E., and Hensley, S.: Displacement field and slip distribution of the 2005 Kashmir earthquake from SAR imagery, Geophys. Res. Lett., 33, L20310, doi:10.1029/2006GL027193, 2006.

Peduzzi, P.: Landslides and vegetation cover in the 2005 North Pakistan earthquake: a GIS and statistical quantitative approach, Nat. Hazards Earth Syst. Sci., 10, 623-640, doi:10.5194/nhess10-623-2010, 2010.

Pesaresi, M. and Benediktsson, J. A.: A new approach for the morphological segmentation of high-resolution satellite imagery, IEEE T. Geosci. Remote 39, 309-320, 2001.

Richards, J. A.: Remote Sensing Digital Image Analysis: An Introduction, Springer-Verlag, Berlin, Germany, 1986.

Rosin, P. L. and Hervàs, J.: Remote sensing image thresholding methods for determining landslide activity, Int. J. Remote Sens., 26, 1075-1092, 2005.

Rossetto, T. and Peiris, N.: Observations of damage due to the Kashmir earthquake of October 8, 2005 and study of current seismic provisions for buildings in Pakistan, B. Earthq. Eng., 7, 681699, 2009

Saito, K., Spence, R. J. S., Going, C., and Markus, M.: Using highresolution satellite images for post-earthquake building damage assessment: A study following the 26 January 2001 Gujarat earthquake, Earthq. Spectra, 20, 145-169, 2004.

Sato, H. P., Hasegawa, H., Fujiwara, S., Tobita, M., Koarai, M., Une, H., and Iwahashi, J.: Interpretation of landslide distribution triggered by the 2005 Northern Pakistan earthquake using SPOT 5 imagery, Landslides, 4, 113-122, 2007.
Serra, P., Pons, X., and Saurì, D.: Post-classification change detection with data from different sensors: Some accuracy considerations, Int. J. Remote Sens., 24, 3311-3340, 2004.

Soille, P.: Morphological Image Analysis - Principles and Applications, 2nd edn., Springer-Verlag, Berlin, Germany, 2008.

Stramondo, S., Bignami, C., Chini, M., Pierdicca, N., and Tertulliani, A.: The radar and optical remote sensing for damage detection: Results from different case studies, Int. J. Remote Sens., 27, 4433-4447, 2006

Stramondo, S., Chini, M., Salvi, S., Bignami, C., Zoffoli, S., and Boschi, E.: Ground Deformation Imagery of the May Sichuan Earthquake, EOS T. Am. Geophys. Un., 89, 341-342, 2008.

Sunar Erbek, F., Ozkan, C., and Taberner, M.: Comparison of maximum likelihood classification method with supervised artificial neural network algorithms for land use activities, Int. J. Remote Sens., 25, 1733-1748, 2004.

Tapponnier, P., King, G., Bollinger, L., and Grasso, J.: Surface faulting during the October 8th, 2005, Muzaffarabad earthquake and Coulomb stress increase on the Jhelum fault, Seismological Society of America, SSA06: San Francisco, April 18-22, 2006.

Tarantino, C., Blonda, P., and Pasquariello, G.: Application of change detection techniques for monitoring man-induced landslide causal factors, Proc. IEEE/IGARSS 2004, 2, 1103-1106, 2004.

The U.S. National Academies Reconstruction Assistance Team Trip Report, 2006. Response to the Pakistan Earthquake of October 8, 2005, June 12-17, 2006 Islamabad, Pakistan, available at: www7.nationalacademies.org/dsc/Quake_Report_2006. pdf (last access: 15 September 2010), 2006.

Vinod, K., Martha, T. R., and Roy, P. S.: Mapping damage in the Jammu and Kashmir caused by 8 October 2005 Mw 7.3 earthquake from the Cartosat-1 and Resourcesat-1 imagery, Int. J. Remote Sens., 27, 4449-4459, 2006.

Yamazaki, F., Matsuoka, M., Kouchi, K., Kohiyama, M., and Muraoka, N.: Earthquake damage detection using high-resolution satellite images, Proc. IEEE IGARSS 2004, 4, 2280-2283, 2004.

Yeats, R. S., Hussain, A.: Surface Features of the Mw 7.6, 8 October 2005 Kashmir Earthquake, Northern Himalaya, Pakistan: Implications for the Himalayan Front, Seismological Society of America, SSA06: San Francisco, April 18-22, 2006.

Yonezawa, C. and Takeuchi, S.: Decorrelation of SAR data by urban damage caused by the 1995 Hoyogoken-Nanbu earthquake, Int. J. Remote Sens., 22, 1585-1600, 2001.

Zhong, P. and Wang, R.: Using combination of statistical models and multilevel structural information for detecting urban areas from a single gray-level image, IEEE T. Geosci. Remote, 45, 1469-1482, 2007 